\title{
Effects of aromatizable and nonaromatizable androgens on the sex inversion of red-spotted grouper (Epinephelus akaara)
}

\author{
Guang-Li Li ${ }^{1,2, \dagger}$, Xiao-Chun Liu ${ }^{1}$ and Hao-Ran Lin ${ }^{1, *, \dagger}$ \\ ${ }^{1}$ Institute of Aquatic Economic Animals and Guangdong Provincial Key Laboratory for Aquatic Economic \\ Animals, College of Life Sciences, Zhongshan (Sun Yat-Sen) University, Guangzhou, 510275, P. R. China; \\ ${ }^{2}$ Fisheries College, Guangdong Ocean University, Zhanjiang, 524025, China; *Author for correspondence: \\ (Phone: +86-20-84113791; Fax: +86-20-84113717; E-mail: ls32@zsu.edu.cn)
}

Received 12 April 2005; Accepted 4 December 2005

Key words: aromatase inhibitor, Epinephelus akaara, methyltestosterone, methyldihydrotestosterone, sex inversion, sex steroids

\begin{abstract}
The effects of aromatizable 17 $\alpha$-methyltestosterone (MT) and non-aromatizable 17 $\alpha$-methyldihydrotestosterone (MDHT) on sex inversion in red-spotted grouper, Epinephelus akaara, were investigated. Fish were implanted with MT, MDHT and MT + AI (aromatase inhibitor, AI) respectively for one month. The results showed that the three treated groups turned into transitional stage with intersex gonads, which contained atretic oocytes and spermatogenic germ cells at all stages of spermatogenesis. The controls did not change sex. The gonads of more than half MT-implanted fish were in early transitional stages of sex inversion, whereas those of more than half MDHT and MT + AI-implanted fish were in late transitional stages of sex inversion. No difference in serum estradiol-17 $\beta\left(\mathrm{E}_{2}\right)$ levels between the controls and the treated groups were observed, whereas 11-ketotestosterone (11-KT) and testosterone (T) levels increased in all treated groups. Significantly lower gonadosomatic index (GSI) and gonadal aromatase activity were observed in the treated groups, which were in accordance with the lower mRNA expression of P450aromA. However, P450aromB mRNA expression increased in the MT group, while it did not change in the MDHT group. These results suggest that the sex inversion of red-spotted grouper by MT and MDHT implantation might be due to the suppression of P450aromA gene expression, and resulting in both the decrease of the ovarian estrogen -secretion, as well as the increase in the 11-KT levels. Furthermore, the main reason for MT being less effective than MDHT might be due to partial aromatization of MT to estrogen.
\end{abstract}

\section{Introduction}

Yamamoto and Kajishima (1969) reviewed systematically the sex determination mechanism of fish. They summarized the historical information on gonadal types, hermaphroditism, genetic sex determination, and the influence of sex steroids on sex differentiation, and suggested that androgens and estrogens are natural sex inducers, of which

\footnotetext{
${ }^{\dagger}$ The authors contributed equally to this study.
}

estrogens being female inducers, and androgens being male inducers.

$17 \alpha$-Methyltestosterone (MT) is considered an effective, and therefore widely used androgen in inducing sex inversion in teleosts. Functional males with spermiation have been obtained by oral administration of exogenous MT in Japanese flounder, Paralichthys olivaceus (Kitano et al. 2000) and grouper, Epinephelus septemfasciatus (Tanaka et al. 2000). Implantation appeared to be more effective compared to oral administration (Tanaka et al. 2000). However, high dose or 
long-term treatment with MT might result in higher proportion of females in fish (Piferrer and Donaldson 1991; Piferrer et al. 1994). Two causes might explain this phenomenon, (a): aromatization of exogenous androgen to estrogen, and (b): inhibition of the biosynthesis of the endogenous androgen in genetic males.

$17 \alpha$-Methyldihydrotestosterone (MDHT) is the methylated form of $5 \alpha$-dihydrotestosterone (DHT). Its unique difference from MT is the presence of $5 \alpha$-reduction, which prevents aromatazation. In salmon,Oncorhynchus kisutch (Piferrer and Donaldson 1991; Piferrer et al. 1994; Lee et al. 2004), brook trout, Salvelinus fontinalis (Galbreath et al. 2003), Nile tilapia, Oreochromis niloticus (Gale et al. 1999; Wassermann and Afonso 2003) and European sea bass, Dicentrarchus labrax (Blazquez et al. 2001), MDHT treatment resulted in a higher proportion of sex-inversed males than MT treatment. However, co-administration of MT with aromatase inhibitor results in significant masculinization (97-98\%) (Piferrer et al. 1994).

Red-spotted grouper, Epinephelus akaara, belongs to the protogynous hermaphrodite fish species. It undergoes sex reversal from female to male. Under natural conditions, the female fish reach first sexual maturity at the age of 2 or 3 years, while sex reversal takes place at the age of 5-6 years. Mature female red-spotted grouper are readily obtainable from captive stock, but the simultaneous availability of mature male redspotted grouper is the most significant constraint to artificial propagation.

The present study was designed to compare the effects of aromatizable and nonaromatizable androgens on inducing sex inversion in red-spotted grouper. Aromatizable 17 $\alpha$-methyltestosterone (MT) and nonaromatizable $17 \alpha$-methyldihydrotestosterone (MDHT) were chosen because of their higher androgenic power compared to their naturally occurring counterparts $\mathrm{T}$ and DHT. Three-year-old female red-spotted grouper were implanted with MT, MDHT or MT in combination with the aromatase inhibitor Fadrozole, respectively. The serum levels of the sex steroid hormones (estradiol-17 $\beta, \mathrm{E}_{2}$; testosterone, $\mathrm{T}$; 11-ketotestosterone, 11-KT), the gonadal aromatase activity, P450arom mRNA (P450aromA in gonads and $\mathrm{P} 450$ arom $\mathrm{B}$ in pituitary) expression, together with the changes in gonadal structures during the period of artificial induced sex inversion were investigated.

\section{Materials and method}

\section{Experimental fish}

Three-year-old female red-spotted groupers (body weight, 460-710 g, body length, 25.5-31 cm) were obtained from Guangdong Daya Bay Fishery Development Center (Huizhou City, Guangdong, P. R. China) where all the experimental fishes were reared in cages under semi-natural conditions. The water temperature during experiment (from May to June) was $27.9 \pm 1.0^{\circ} \mathrm{C}$. Fish were fed with frozen trash fish once a day.

\section{Experimental design and sampling procedures}

17 $\alpha$-Methyltestosterone (Sigma Chemical Co.), 17 $\alpha$-methyldihydrotestosterone (Molecular Devices Co., USA), and the non-steroidal aromatase inhibitor, Fadrozole (AI, a gift from Novartis Pharma Co.) were mixed respectively with elastomer and curing agent (MDX4-4210, Dow Corning Co.) and left overnight at room temperature to set. Three-year-old female red-spotted grouper $(n=20)$ were divided equally into four groups: controls, MT, MDHT and MT+AI groups, respectively. The experimental fish were intraperitonally implanted with $10.0 \mathrm{mg} / \mathrm{kg}$ BW of MT, MDHT or MT plus $1.0 \mathrm{mg} / \mathrm{kg}$ BW of AI, respectively.

Four weeks after implantation, blood samples were taken with a sterile syringe from each fish by puncturing the caudal vasculature, and serum was separated by centrifugation and then stored at $-20{ }^{\circ} \mathrm{C}$ for analysis of sex steroids. Pituitary and gonadal tissues were quickly dissected and frozen in liquid nitrogen, and then stored at $-70{ }^{\circ} \mathrm{C}$ for later analysis of aromatase activity and P450arom mRNA expression. A piece from the central part of the gonad was fixed in Bouin's solution, embedded in paraffin and sectioned at $6 \mu \mathrm{m}$. Transverse sections were stained with hematoxylin and eosin. Developmental stages of germ cells were examined. Total body weight and gonadal weight were measured for the calculation of gonadosomatic index $(\mathrm{GSI}=$ gonadal weight/body weight $\times 100)$.

\section{Sex steroid assays}

Estradiol-17 $\beta \quad\left(\mathrm{E}_{2}\right)$ and testosterone (T) were determined by radioimmunoassay (RIA), while 
11-KT by enzyme-linked immunosorbent assay (ELISA). $\mathrm{T}$ and $\mathrm{E}_{2}$ Kits were purchased from Beijing North Biological Technical Research Institute, and 11-KT from Cayman Chemical Company. The sensitivities of the assay for $E_{2}, T$ and $11-\mathrm{KT}$ were 2,20 and $3 \mathrm{pg} / \mathrm{ml}$, respectively. Intra-assay and inter-assay variation for the steroids were below $11.4 \%$ and $27.0 \%$, respectively. The hormone assays were performed following the manufacturer's instructions.

\section{Measurement of aromatase activity}

Aromatase activity in the gonad was measured by a radiometric method modified from previous studies (Lee et al. 2000). Gonads were homogenized with potassium phosphate buffer and centrifuged at $1000 \mathrm{~g}$ for $10 \mathrm{~min}$ at $4{ }^{\circ} \mathrm{C}$. The crude supernatant fraction was supplied with $100 \mu$ of cofactor solution and 600 radiolabelled $\mathrm{nM}$ androst-4-ene-3, 17-dione, $\left[1 \beta-{ }^{3} \mathrm{H}(\mathrm{N})\right]-(936.1 \mathrm{GBq} /$ mmol, Perkin Elmer Life Sciences, Inc., Boston). The reaction mixture was incubated at $28^{\circ} \mathrm{C}$ for $80 \mathrm{~min}$; the reaction was terminated by adding $10 \%$ trichloroacetic acid. After centrifugation, the supernatant was two times extracted with a charcoal emulsion (80 $\mathrm{mg}$ charcoal $/ \mathrm{ml}$ in $10 \%$ trichloroacetic acid) to remove the excess of un-reacted androst-4-ene-3, 17-dione, $\left[1 \beta-{ }^{3} \mathrm{H}(\mathrm{N})\right]$ . The radioactivity was measured by liquid scintillation. The protein concentration of the crude supernatant fraction was measured with a Bio-Rad protein assay kit (Bio-Rad Co.). Aromatase activity was expressed as pmol ${ }^{3} \mathrm{H}_{2} \mathrm{O} /$ h.mg protein.

\section{P450aromA and P450aromB $m R N A$ expression}

Total RNA was extracted using TRIzol (Invitrogen) from pituitary and gonads of fish at the end of the experiment. The total RNA was first treated with RNase-free DNaseI (1 U/ $/ \mu$ g of total RNA; Invitrogen) to remove any genomic DNA contamination. P450aromA and P450aromB mRNA in each RNA sample were amplified by P450aromspecific reverse transcription-polymerase chain reaction (RT-PCR) ( $\mathrm{Li}$ et al. 2004). The oligonucleotides used as PCR primers were the following:

P450aromB: 5'-TGACACCTGGCAAACAGTTC-3' (forward primer); 5'-GATGGTGTCGTCTTCCAGAG-3' (reverse primer).
P450aromA: 5'-GGAGACATTGTGAGAGTCTGGATC-3' (forward primer); 5'-TGACAGGTACATCCAGGAAGAGTC-3' (reverse primer).

$\beta$-actin: 5'-GATCATGTTCGAGACCTTCAACAC-3' (forward primer) ; 5'-TCCGATCCAGACAGAGTATTTACG-3' (reverse primer).

PCRs for P450arom were conducted at $94{ }^{\circ} \mathrm{C}$ (0.5 min), $55{ }^{\circ} \mathrm{C}(0.5 \mathrm{~min}), 72{ }^{\circ} \mathrm{C}(1 \mathrm{~min})$ for 33 cycles, but that for $\beta$-actin were conducted for 24 cycles. The expected length of P450aromB, P450aromA and $\beta$-actin were 484, 386 and $660 \mathrm{bp}$, respectively. The products were electrophoresed on $1.7 \%$ agarose gel. Relative quantities were determined with $\mathrm{P} 450$ arom and $\beta$-actin.

Data analysis

All data were represented as means \pm standard error of the mean (mean \pm S.E.M), and subjected to one-way analysis of variance followed by Duncan's multiple rang test. Differences were considered significantly when $p<0.05$.

\section{Results}

\section{Gonadosomatic index (GSI) and histological changes in gonads}

At the end of the experiment, the GSIs of the MT, MDHT and MT + AI-implanted fish were significantly lower than that in the initial controls, as well as that in the controls at the end of the experiment, due to the degeneration of oocytes and simultaneous proliferation of spermatogenic germ cells. In addition, the GSIs of the controls at the end of the experiment were lower in comparison to the initial controls because of the later stage of the breeding season (Figure 1).

Histological examination showed that the ovary of the initial control females had oocytes at the previtellogenic stages (middle of May) (Figure $2 \mathrm{a}$ ), while the oocytes were loosely arranged and degenerated at the end of the experiment (Figure 2b). In contrast, gonads exhibiting intersex-transition were observed in the three treated groups. Gonads at early transitional phase were characterized by the degeneration of oocytes and simultaneous proliferation of spermatogenic germ 


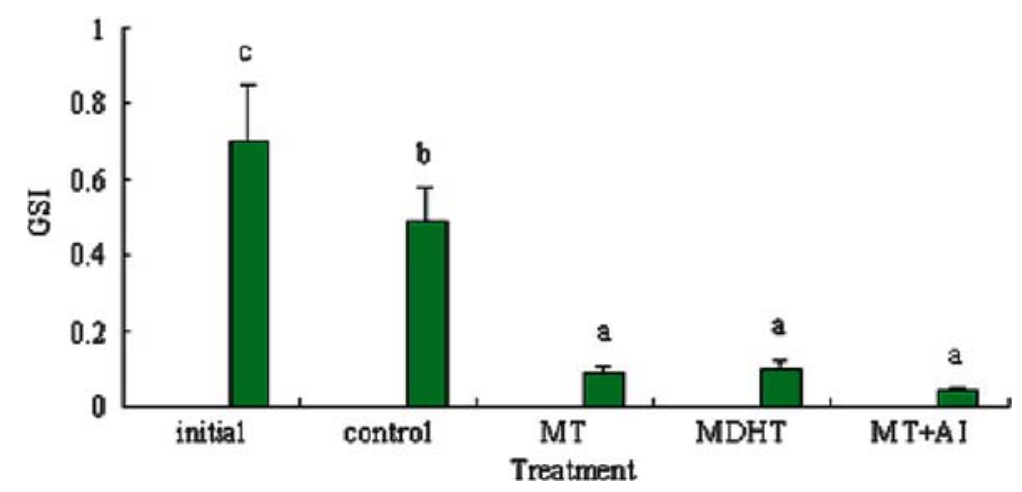

Figure 1. Effects of MT, MDHT and MT + AI on GSI in Epinephelus akaara $(n=5)$. Values with different letters indicate significant differences $(P<0.05)$ within the data.

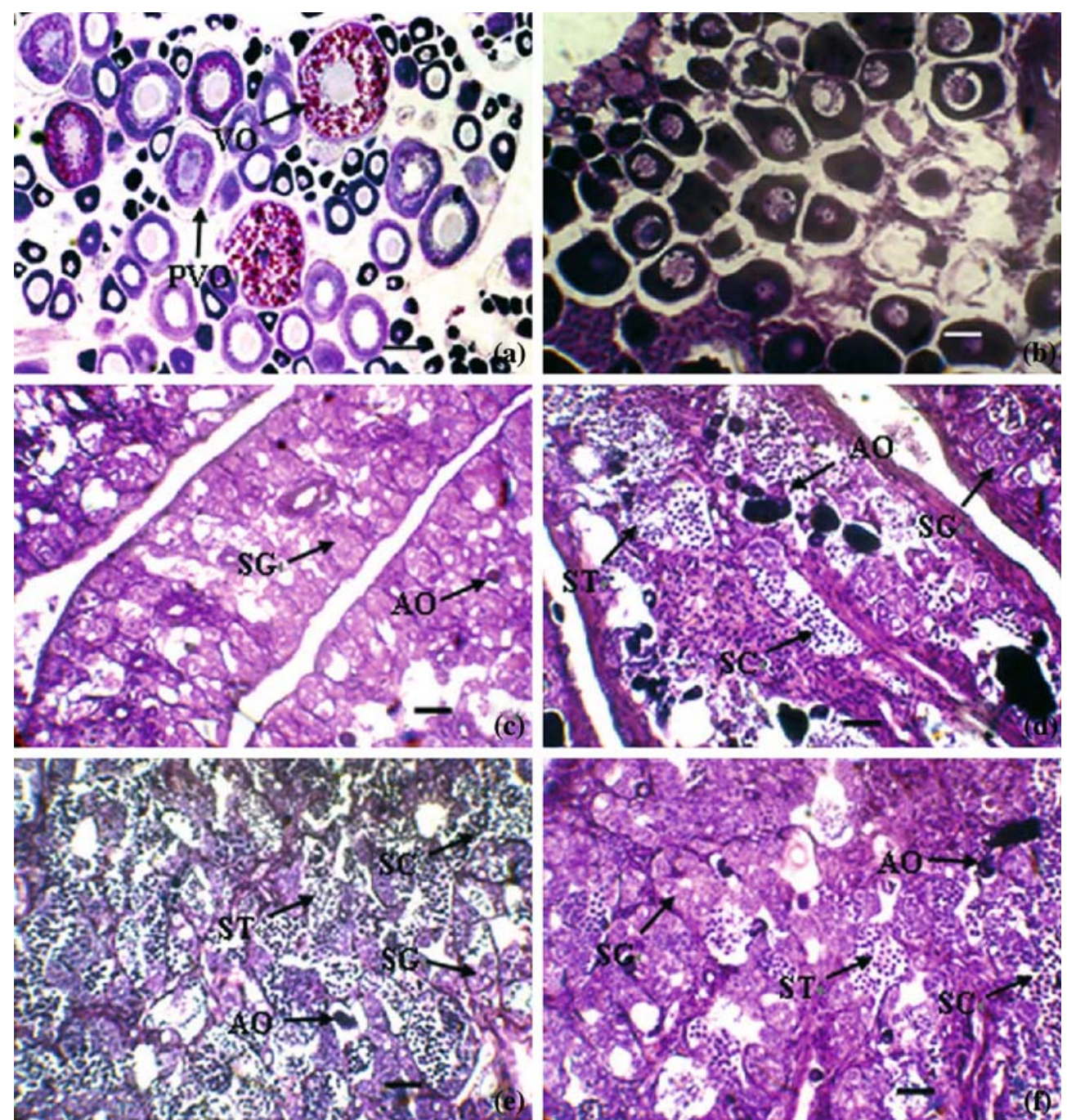

Figure 2. Gonadal histology of Epinephelus akaara implanted with MT, MDHT and MT + AI (a) initial control; (b) vehicle; (c) early transitional gonad; (d) late transitional gonad in MT group; (e) late transitional gonad in MDHT group; (f) late transitional gonad in MT + AI group; Abbreviation: AO, atretic oocyte; PO, perinucleolar oocyte; PVO, previtellogenic oocyte; SG, spermatogonia; SC, spermatocyte; ST, spermatid; a: Scale bar $=250 \mu \mathrm{m}$; b: Scale bar $=100 \mu \mathrm{m}$; c-f: Scale bar $=50 \mu \mathrm{m}$. 
cells. As degeneration progressed, atretic oocytes were absorbed and the proliferation of spermatogenic germ cells increased further towards the central region of ovarian lamellae (Figure 2c). Gonads at late transitional phase were characterized by various phases of spermatogenic germ cells from spermatocytes to spermatids, and only a few atretic oocytes had remained (Figure $2 d-f$ ).

The gonads of more than half of the MTimplanted fish were at early transitional stages of sex inversion, whereas those of more than half of the MDHT and MT + AI-implanted fish were at late transitional stages of sex inversion (Figure 3).

\section{Changes in the serum levels of sex steroid hormones}

Serum levels of sex steroid hormones are shown in Figure4. Compared to the initial controls, 11-KT and $E_{2}$ levels decreased significantly in the controls. The highest 11-KT levels were observed in the MDHT group, followed by the levels in the $\mathrm{MT}+\mathrm{AI}$ group, while the lowest values were found in the MT group. 11-KT in the three treated groups were significantly higher compared to the control group $(P<0.05)$. In the $\mathrm{MT}$ and $\mathrm{MT}+\mathrm{AI}$ group $\mathrm{T}$ levels were significantly higher compared to the control group. However, serum $\mathrm{E}_{2}$ levels were not different between the controls and the three treated groups.

\section{Changes in the aromatase activity in gonads}

Gonadal aromatase activity decreased significantly in the MT, MDHT and MT + AI-implanted group
$(P<0.05)$ (Figure5), but no significant differences were observed between the three treated groups.

\section{P450aromA and P450aromB expression}

P450aromB encoding mRNA increased in the MT group, decreased in the MT + AI group, but it did not change in the MDHT group (Figure 6). Conversely, the amount of P450aromA encoding mRNA was strongly decreased in the three treated groups (Figure7). Relative of P450aromA and P450aromB mRNA levels over $\beta$-actin are shown in Table1.

\section{Discussion}

Two distinct cytochrome P450 aromatase cDNAs that derive from separate loci are differentially expressed in pituitary (P450aromB $\gg$ P450aromA) and $\operatorname{gonad}(\mathrm{P} 450$ aromB $\ll \mathrm{P} 450$ arom $\mathrm{A}$ ) ( $\mathrm{Li}$ et al. 2004). The present study showed that the amount of P450aromA mRNA in the gonads decreased significantly after MT, MDHT and $\mathrm{MT}+\mathrm{AI}$ implantation, which was in accordance with the significant decline of gonadal aromatase activity. Suppression of P450arom gene expression was also found in gonads of sex-reversed, genetypically female Japanese flounder treated with MT and AI (Kitano et al. 2000). However, the amount of P450aromB mRNA increased in the pituitary in the MT-implanted fish, decreased in the MT+AIimplanted fish, but it did not change in the MDHT

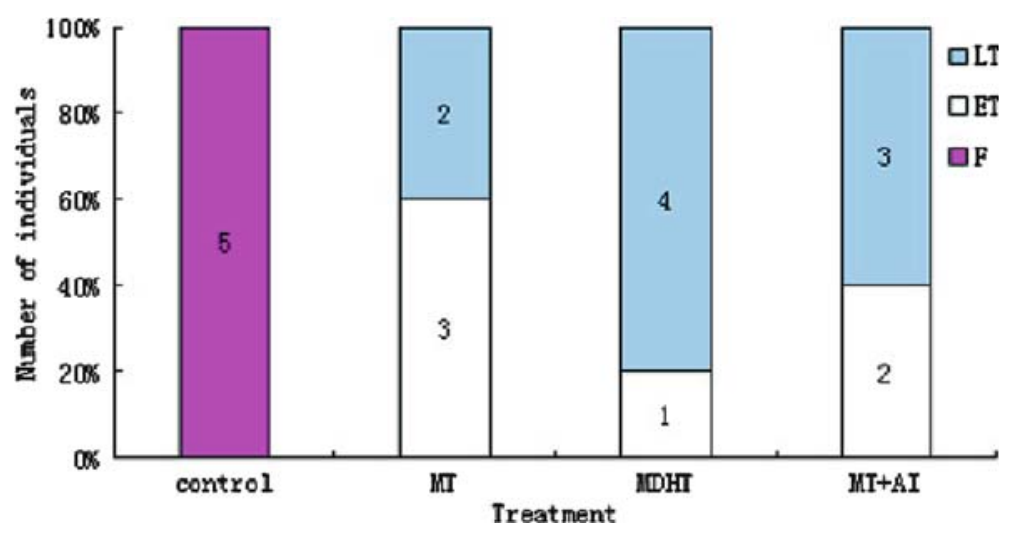

Figure 3. Sex ratio of Epinephelus akaara implanted with MT, MDHT and MT + AI. Abbreviations: F, Female; ET, Early transitional phase; LT, late transitional phase. Numbers in bars indicate the total number of fish. 

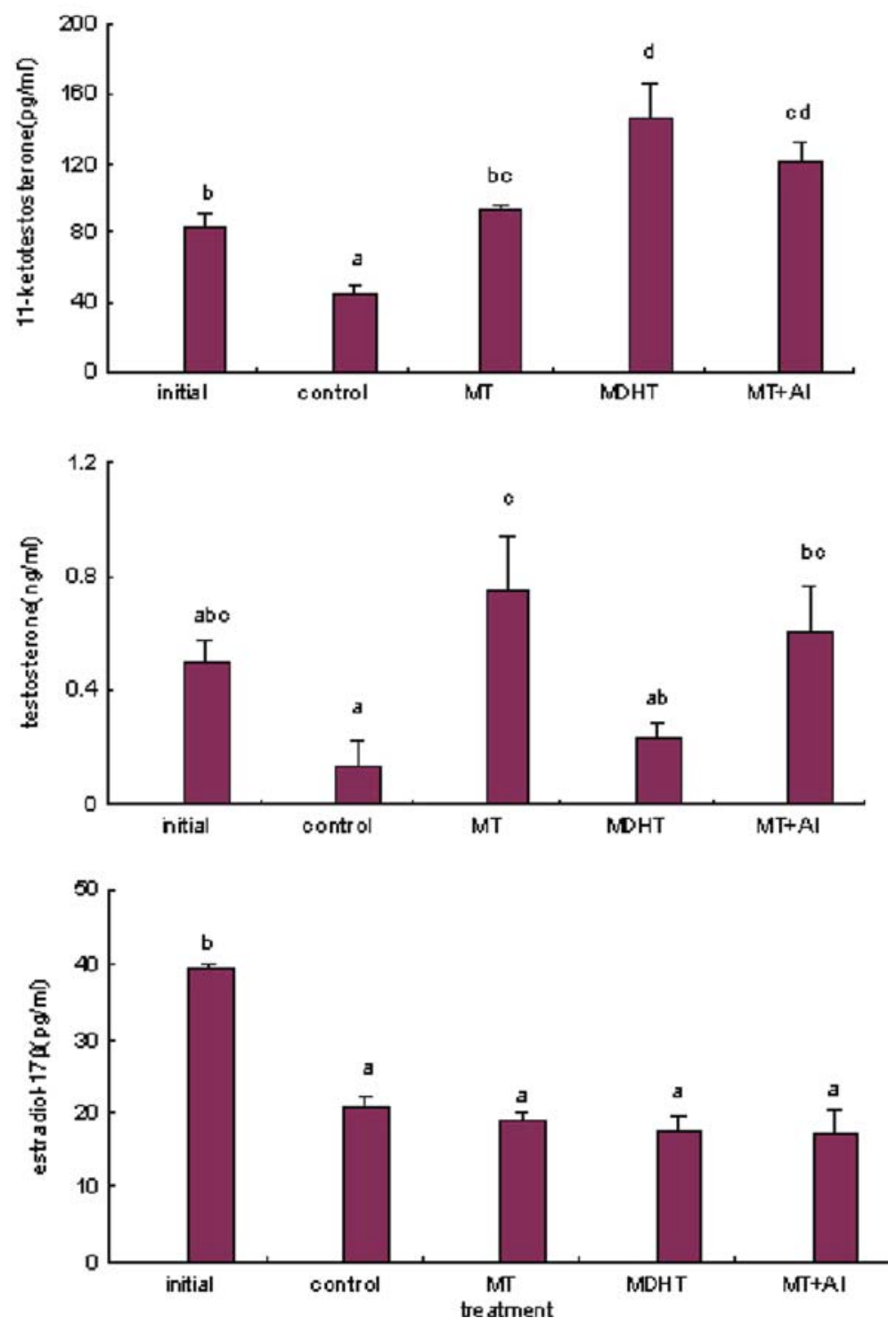

Figure 4. Effects of MT, MDHT and MT + AI on serum sex steroids in Epinephelus akaara $(n=5)$. Values with different letters indicate significant differences $(P<0.05)$ within the data.

group in red-spotted grouper. In teleosts, it has been shown that estrogen mediated the up-regulation of P450aromB expression, but not of P450aromA (Callard et al. 2001). Because the only difference between MT and MDHT is the possibility to be aromatized, the increased P450aromB expression in the MT group in red-spotted grouper might be the result from MT aromatization. Furthermore, the decreased amount of P450aromB mRNA in the MT+AI group demonstrated that estrogen, aromatized from MT, participated in the regulation of $\mathrm{P} 450$ arom $\mathrm{B}$, and suggested that $1.0 \mathrm{mg} / \mathrm{kg}$ BW of AI was enough to prevent the conversion of MT into estrogen, thus counteracting to a certain degree the increase of P450aromB gene expression that was caused by MT.

Aromatase is the only known enzyme able to catalyze the irreversible conversion of androgen into estrogen. In the present study, significantly decreased aromatase activity and P450aromA gene 


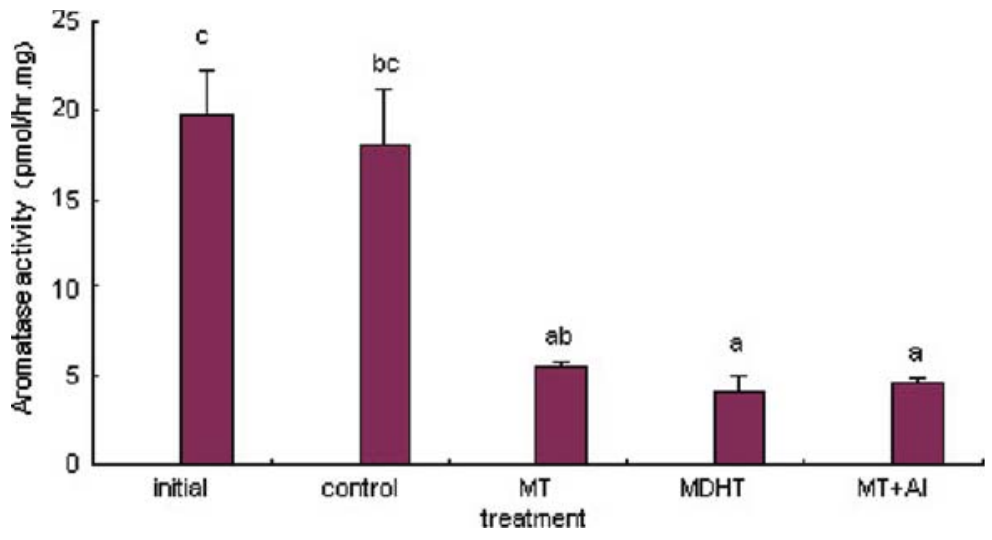

Figure 5. Effects of MT, MDHT and MT + AI on gonadal aromatase activity in Epinephelus akaara $(n=5)$. Values with different letters indicate significant differences $(P<0.05)$ within the data.

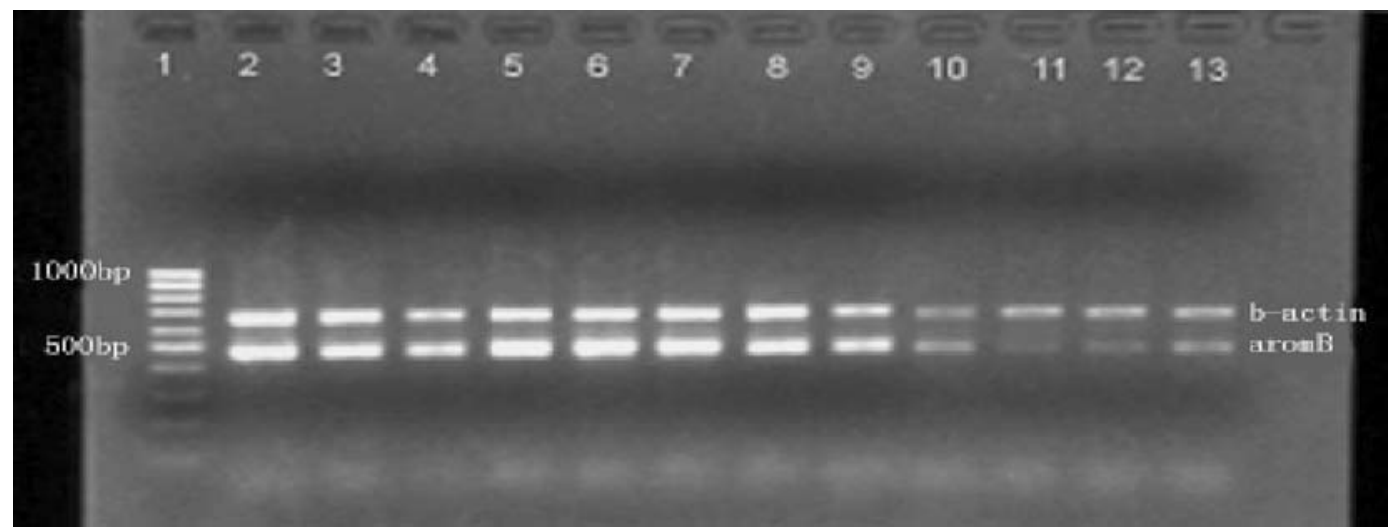

Figure 6. Semi-quantitative RT-PCR analysis of P450aromB ( 33 cycles) and $\beta$-actin ( 24 cycles) mRNAs in the pituitary in the controls and MT, MDHT and MT + AI-implanted Epinephelus akaara 1: marker; 2-4: controls; 5-7: MT-implanted; 8-10: MDHT-implanted; 11-13: MT+AI-implanted.

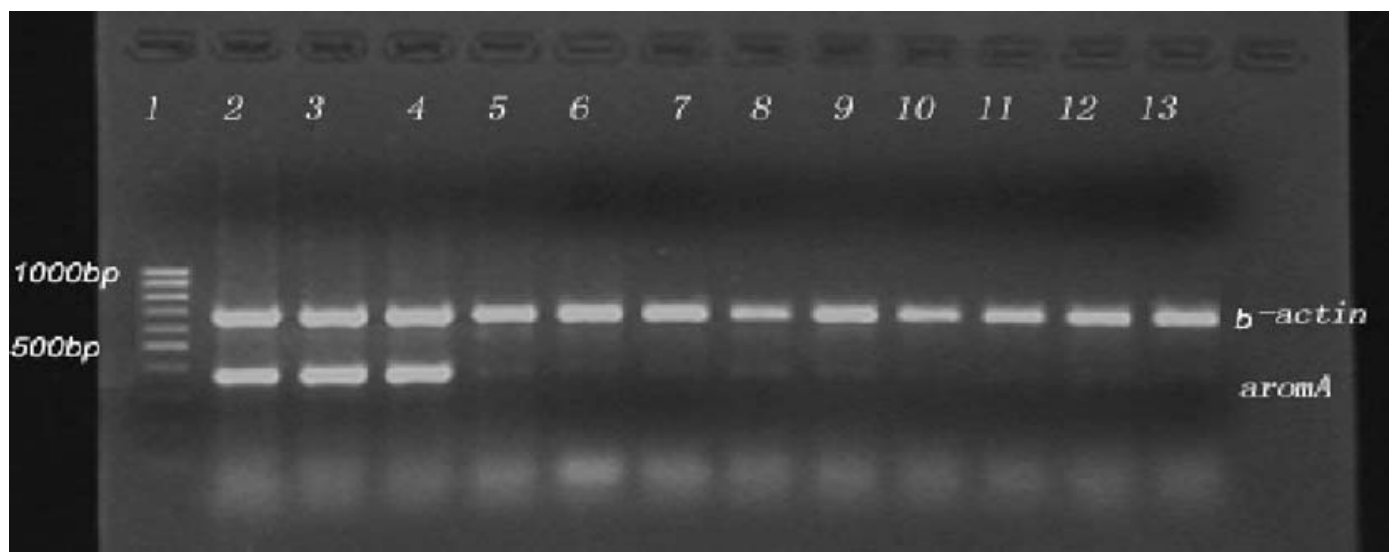

Figure 7. Semi-quantitative RT-PCR analysis of P450aromA ( 33 cycles) and $\beta$-actin ( 24 cycles) mRNAs in the gonad in the controls and MT, MDHT and MT + AI-implanted Epinephelus akaara The sample sheet as Figure 6. 
Table 1. Relative mRNA levels of P450aromA and P450aromB over $\beta$-actin in the controls and MT, MDHT and MT + AIimplanted Epinephelus akaara

\begin{tabular}{lll}
\hline & P450aromA & P450aromB \\
\hline Control & $1.270 \pm 0.130^{\mathrm{b}}$ & $1.050 \pm 0.076^{\mathrm{b}}$ \\
MT & $0.094 \pm 0.022^{\mathrm{a}}$ & $1.445 \pm 0.072^{\mathrm{c}}$ \\
MDHT & $0.174 \pm 0.037^{\mathrm{a}}$ & $1.157 \pm 0.133^{\mathrm{b}}$ \\
MT + AI & $0.065 \pm 0.013^{\mathrm{a}}$ & $0.572 \pm 0.051^{\mathrm{a}}$ \\
\hline
\end{tabular}

Values with different letters indicate significant differences $(P<0.05)$ within the data.

expression in the three treated groups suggested that the decreased $E_{2}$ levels are the result of the degeneration of ovarian follicles. Serum $E_{2}$ levels were significantly lower in the final controls compared to the initial controls, which is in accordance with the degeneration of ovarian follicles at the end of the breeding season. However, the lower serum $\mathrm{E}_{2}$ levels in the three treated groups must be ascribed to the decrease in aromatase activity and P450aromA gene expression in the gonads. No significant differences in serum $\mathrm{E}_{2}$ levels were observed between the controls and the three treated groups, which suggests that variations in circulating androgen levels were responsible for the changes in gonadal aromatase activity.

In the present study, the proportion of gonads in late transitional stages in the MT-implanted group was lower than that in the MDHT and MT+AI-implanted group. Because MT can be aromatized whereas MDHT cannot, estrogen aromatized from MT might weaken the masculinizing effect of MT. Combination of MT treatment with AI was more potent in terms of promoting sex reversion than MT alone, which suggests that $1.0 \mathrm{mg} / \mathrm{kg} \mathrm{BW}$ of AI was sufficient to prevent the aromatization of MT.

At the end of the experiment, serum sex steroids levels in the controls were lower than those in the initial controls, which might be due to the higher water temperature in June. Gonads began to degenerate at the end of the breeding season, and serum sex steroids at this stage decreased.

The present study showed that 11-KT increased significantly in the three treated groups, while $\mathrm{T}$ increased significantly only in the MT and MT+AI-implanted groups. No significantly increased $\mathrm{T}$ levels, but a significant masculinizing effect was observed in the MDHT group, which suggested that $11-\mathrm{KT}$ might play a important role than $\mathrm{T}$ in inducing sex inversion in the red-spotted grouper.

Lee et al. (1995) suggested that the sex inversion of Epinephelus tauvina induced by sustained release MT results from its direct effect on the ovary and/or a positive feedback by MT on the hypothalamus-pituitary axis, resulting in an increase of gonadotropin production. Our data suggest that the main action of MT and MDHT in inducing sex inversion was the suppression of aromatase activity and P450aromA gene expression in gonads, resulting in a decrease of the amount of ovary-secreted estrogen, accompanied by degeneration of ovarian follicles, and subsequently, proliferation of spermatogenic germ cells after the elevation of 11-KT.

In conclusion, the sex inversion of red-spotted grouper by MT and MDHT might be due to the suppression of P450arom gene expression and the consequence of a decrease in the amount of ovarysecreted estrogen as well as increased serum 11-KT levels. The main reason for MT being less effective than MDHT is due to a partial aromatization of MT into estrogen.

\section{Acknowledgments}

This work was supported by the National Marine 863 Projects of China (Nos. 2001AA621010), the National Natural Science Foundation of China (No. 39970586), Key Project of Scientific and Technological Research of the Ministry of Education (No. 02150) and Project of Scientific and Technological scheme of Guangdong Province (No. 2001AA621010). Authors thank Novartis Pharma for the aromatase inhibitor (Fadrozole) gift. Thanks also to Shu, H., Xie, J., Yang, J.P. for the assistance and the staff of Guangdong Daya Bay Fishery Development Center for the rearing of fish.

\section{References}

Blazquez, M., Felip, A., Zanuy, S., Carrillo, M. and Piferrer, F. 2001. Critical period of androgen-inducible sex differentiation in a teleost fish, the European sea bass. J. Fish Biol. 58(2): 342-358.

Callard, G.V., Tchoudakova, A.V., Kishida, M. and Wood, E. 2001. Differential tissue distribution, developmental programming, estrogen regulation and promoter characteristics of cyp 19 genes in teleost fish. J Steroid Biochem. Mol. Biol. 79: 305-314. 
Galbreath, P.F., Adams, N.D. and Sherrill, L.W. III 2003. Successful sex reversal of brook trout with 17alpha-methyldihydrotestosterone treatments. North Am. J. Aquacult. 65(3): 235-239.

Gale, W.L., Fitzpatrick, M.S., Lucero, M., Contreras-Sanchez, W.M. and Schreck, C.B. 1999. Masculinization of Nile tilapia (Oreochromis niloticus) by immersion in androgens. Aquaculture 178(3-4): 349-357.

Goudie, C., Render, B.D., Simco, A. and Davis, K.B. 1983. Feminization of channel catfish by oral administration of steroid sex hormones. Trans. Am. Fish. Soc. 112: 670-672.

Kitano, T., Takamune, K., Nagahama, Y. and Abe, S.I. 2000. aromatase inhibitors and 17a-methytestosterone cause sexreversal from genetical female to phenotypic males and suppression of $\mathrm{P} 450$ aromatase gene expression in Japanese flounder (Paralichthys olivaceus). Mol. Reprod. Dev. 56: 1-5.

Lee, S.T.L., Kime, D.E., Chao, T.M., Lim, H.S., Chou, R., Lam, T.J. and Tan, C.H. 1995. In virto metabolism of testosterone by gonads of grouper (Epinephelus tauvina) before and after sex inversion with $17 \alpha$-Methyltestosteron. Gen. Comp. Endocrinol. 99: 41-49.

Lee, Y.H., Lee, F.Y., Yueh, W.S., Tacon, P., Du, J.L., Chang, C.N., Jeng, S.R., Tanaka, H. and Chang, C.F. 2000. Profiles of gonadal development, sex steroids, aromatase activity, and gonadotropin II in the controlled sex change of protandrous black porgy, Acanthopagrus schlegeli Bleeker. Gen. Comp. Endocrinol. 119(1): 111-120.

Lee, P., King, H. and Pankhurst, N. 2004. Preliminary assessment of sex inversion of farmed Atlantic salmon by dietary and immersion androgen treatments. North Am. J. Aquacult. 66(1): 1-7.
Li, G.L., Liu, X.C., Zhang, Y., Bei, J.X. and Lin, H.R. 2004. Cloning and expression of two cytochrome P450 aromatase genes in red-spotted grouper (Epinephelus akaara). Acta Zoological Sinica 50(5): 791-799.

Piferrer, F. and Donaldson, E.M. 1991. Dosage-dependent differences in the effect of aromatizable and nonaromatizable androgens on the resulting phenotype of coho salmon (Oncorhynchus kisutch). Fish. Physiol. Biochem. 9: 145-150.

Piferrer, F., Zanuy, S., Carrillo, M., Solar, I.I., Devlin, R.H. and Donaldson, E.M. 1994. Brief treatment with an aromatase inhibitor during sex differentiation causes chromosomally female salmon to develop as normal functional males. J. Exp. Zool. 270: 255-262.

Solar I.I. and Donaldson, E.M. 1985. Studies on genetic and hormonal sex control in domesticated rainbow trout. İ. Use of methyltestosterone for masculinization and sterilization in cultured rainbow trout (Salmon gairdnerii Richardson). Can Tech Rep Fish Aquat Sci, 1380.

Tanaka, H., Tsuchihashi, Y. and Kuromiya, Y. 2000. Induction of sex revesal in the sevenband grouper, Epinephelus Septemfasciatus. In: Proceedings of the 6th International Symposium on the Reproductive Physiology of Fish. Bergen, Norway, 1999, pp 423.

Wassermann, G.J. and Afonso, O. 2003. Sex reversal in Nile tilapia (Oreochromis niloticus Linnaeus) by androgen immersion. Aquacult. Res. 34(1): 65-71.

Yamamoto, T. and Kajishima, T. 1969. Sex differentiation. In: Fish physiology. pp. 117-175. Edited by W. Hoar and D. Randall. Academic Press. 